\title{
As novas propostas para a segurança pública no Brasil: uma análise comparativa dos projetos Bolsa Formação e Mulheres da Paz
}

Verônica Sánchez da Cruz Rios; Marcos Cerqueira; Pedro Assumpção Alves e Daniel Gama e Colombo*

\section{Apresentação}

Este artigo foi elaborado com base nas pesquisas e no relatório apresentado pelos autores como resultado final da etapa de Estágio Supervisionado das $13^{a}$ e $14^{a}$ edições do Curso de Formação para a Carreira de Especialista em Políticas Públicas e Gestão Governamental, da Escola Nacional de Administração Pública (ENAP), realizado entre novembro de 2008 e março de 2009.

Trata-se de uma pesquisa eminentemente empírica, que apresenta uma análise descritiva de dois projetos específicos do Programa Nacional de Segurança Pública com Cidadania (Pronasci), do Ministério da Justiça (MJ) - os projetos "Mulheres da Paz" e "Bolsa Formação". O principal objetivo é, a partir da descrição e reconstrução histórica desses projetos, realizar uma comparação entre alguns de seus principais elementos ou características, e concatená-los com conceitos ou abordagens teóricas. 
Os elementos a serem comparados foram selecionados ao longo da pesquisa, com base na identificação de diferenças entre os dois projetos, que poderiam trazer conclusões úteis à análise e formulação de políticas públicas. Partimos, inicialmente, do modelo de ciclo de políticas públicas ${ }^{1}$, mas, para isso, foi necessário complementar esse ferramental a fim de dar conta de outros fatores que se mostraram relevantes nos casos sob estudo. Assim, os pontos a serem comparados (e que perfazem o cerne da discussão aqui travada) são: 1) os vetores ou dimensões da coordenação política, 2) o momento da entrada na agenda governamental, 3) o processo de formulação e implementação, 4) o controle, monitoramento e avaliação, e, por fim, 5) os desafios da institucionalização ou continuidade de cada projeto.

$\mathrm{O}$ artigo encontra-se estruturado da seguinte forma: a primeira parte, após esta apresentação, expõe o método de pesquisa utilizado e as fontes de dados e informações; a segunda traz um panorama geral sobre o Pronasci, enquanto contexto maior no qual podem ser enquadrados os projetos sob estudo; a terceira apresenta uma análise acerca das relações interfederativas, interministeriais e entre as secretarias e departamentos internos do MJ; na quarta é feita a análise sobre o Projeto Bolsa Formação; a quinta, por sua vez, é dedicada ao Mulheres da Paz; e, por fim, a sexta parte realiza a comparação entre os projetos e sintetiza as principais impressões dos pesquisadores.

\section{Aspectos metodológicos e fontes de informação}

A abordagem utilizada neste artigo é eminentemente qualitativa, no sentido de que foram privilegiadas impressões e opiniões dos atores envolvidos, além de informações fáticas e históricas.
Este trabalho tem como base participação em eventos e entrevistas realizadas com atores-chave do MJ e de outros órgãos envolvidos, além da análise de documentos e publicações sobre os projetos. A principal fonte de informações foi uma série de entrevistas informais (não estruturadas) realizadas no período de 16 a 27 de março de 2009 (cerca de 15 entrevistados). Os entrevistados, em sua maioria, eram autoridades e servidores do MJ em exercício nos seguintes departamentos: Secretaria-Executiva do Pronasci, Secretaria de Planejamento, Orçamento e Administração, Secretaria de Assuntos Federativos, Secretaria Nacional de Segurança Pública e Coordenação-geral de Planejamento Setorial. Por fim, especificamente quanto ao projeto Mulheres da Paz, os pesquisadores tiveram a oportunidade de frequentar a $3^{\text {a }}$ Reunião de Monitoramento, realizada no Rio de Janeiro entre os dias 25 e 27 de março de 2009, na qual foi possível ouvir gestores locais e algumas das mulheres beneficiadas.

Ressaltamos que não houve gravação e transcrição das entrevistas, sendo as respostas e informações anotadas pelos pesquisadores para posterior análise de conteúdo.

\section{O Programa Nacional de Segu- rança Pública com Cidadania}

O Programa Nacional de Segurança Pública com Cidadania (Pronasci), desenvolvido pelo MJ, é uma mudança no paradigma da segurança pública que privilegia ações preventivas e a articulação entre diferentes esferas de governo e da sociedade civil. Embora o programa não supere no todo uma abordagem top-down ${ }^{2}$, apresenta méritos indiscutíveis para o 
avanço do diálogo federativo rumo a um modelo de governança ${ }^{3}$. Os casos dos projetos Bolsa Formação e Mulheres da Paz são exemplos dessa concepção, possibilitando, no primeiro, a definição de conteúdos educacionais pelos estados e municípios, e incorporando, no segundo, a importância dos gestores locais e da sociedade civil no projeto.

O Pronasci é definido pelo MJ como uma "iniciativa inédita no enfrentamento à criminalidade no país. O projeto articula políticas de segurança com ações sociais; prioriza a prevenção e busca atingir as causas que levam à violência, sem abrir mão das estratégias de ordenamento social e segurança pública" 4 .

Um de seus principais antecedentes foi o modelo de segurança utilizado para a $15^{a}$ edição dos Jogos Pan-americanos, realizada no Rio de Janeiro em 2007. Mas, antes mesmo desse evento, há evidencias de que uma mudança na forma de abordar o tema da segurança pública já estava em curso, como:

I) a criação da Secretaria Nacional de Segurança Pública (Senasp), pelo Decreto $\mathrm{n}^{\circ} 2.315$, de 4 de setembro de 1997, que reconhece a vocação e competência natural dos municípios para a implementação de políticas públicas básicas, especialmente as de prevenção da violência e criminalidade" 5 , e que "tem como uma de suas prioridades o desenvolvimento de ações de prevenção junto aos estados e municípios";

II) o lançamento do Novo Plano Nacional de Segurança Pública (PNSP) em junho de 2000, "que, de forma inédita no Brasil, introduz um planejamento governamental na segurança pública consistente e orientado para as causas do problema"7;

III) a instituição do Fundo Nacional de Segurança Pública (FNSP), por meio da Lei $\mathrm{n}^{\circ}$ 10.201, de 14 de fevereiro de 2001, "com o objetivo de apoiar projetos na área de segurança pública e de prevenção à violência, enquadrados nas diretrizes do plano de segurança pública do governo federal", e apoiando projetos na área de segurança pública "voltados à prevenção da violência e criminalidade, tendo como foco, também, os Objetivos de Desenvolvimento do Milênio - Sistema Nações Unidas";; e

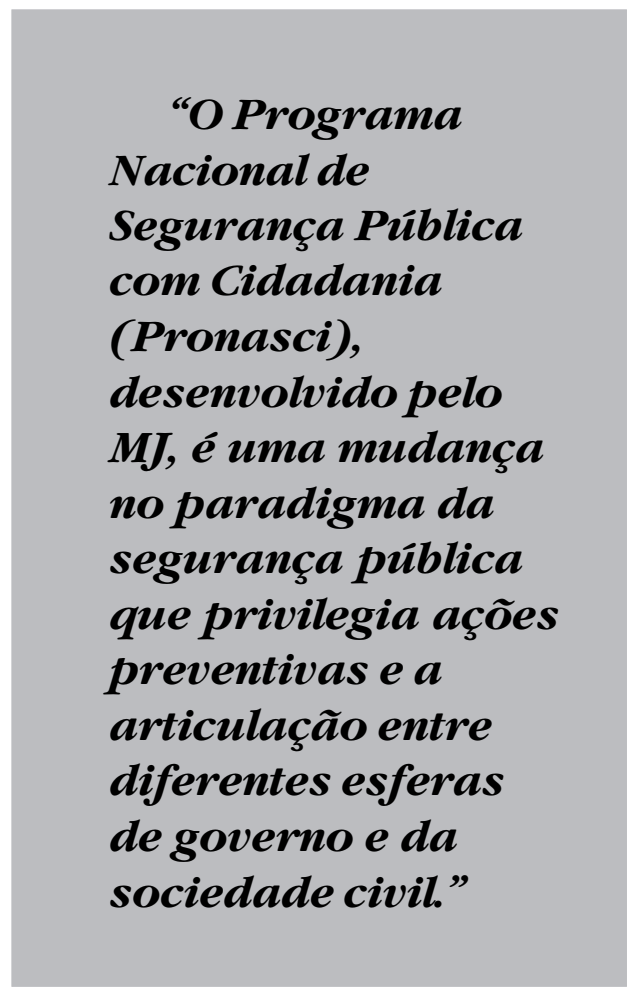

IV) a instituição do Sistema único de Segurança Pública (Susp) em 2003. Conforme descrição no sítio do Ministério da Justiça, o sistema foi "concebido com o objetivo de integrar as ações das polícias nas três esferas do Poder Executivo" " por meio dos Gabinetes de Gestão Integrada Estaduais (GGIE) -"sem gestão integrada não há política de segurança pública eficiente" ${ }^{\prime \prime}$. 
Tais inovações têm como elemento comum os pressupostos de cooperação intergovernamental e da prevenção, que representam mudanças no paradigma de gestão da segurança pública.

A partir dessas experiências, em 2007 é instituído o Programa Nacional de Segurança Pública com Cidadania, por meio da lei $\mathrm{n}^{\circ} 11.530$, de 24 de outubro de 2007.

De acordo com a referida lei, "o Pronasci destina-se a articular ações de segurança pública para a prevenção, controle e repressão da criminalidade, estabelecendo políticas sociais e ações de proteção às vítimas". "Será executado de forma integrada pelos órgãos e entidades federais envolvidos e pelos estados, Distrito Federal e municípios que a ele se vincularem voluntariamente, mediante instrumento de cooperação federativa".

A referida lei dispõe ainda que são focos prioritários dos programas projetos e ações que compõem o Pronasci (art. $4^{\circ}$ da Lei no 11.707, de 2008):

I) foco etário: população juvenil de 15 a 24 anos;

II) foco social: jovens e adolescentes egressos do sistema prisional ou em situação de moradores de rua, famílias expostas à violência urbana, vítimas da criminalidade e mulheres em situação de violência;

III) foco territorial: regiões metropolitanas e aglomerados urbanos que apresentem altos índices de homicídios e de crimes violentos; e

IV) foco repressivo: combate ao crime organizado.

O programa previa, na sua concepção, um investimento total de $\mathrm{R} \$ 6,707$ bilhões até o fim de 2012. Os principais eixos estão divididos em 94 ações, cujas metas mais importantes são: valorização dos profissionais de segurança pública; reestruturação do sistema penitenciário; combate à corrupção policial; e envolvimento da comunidade na prevenção à violência. A Lei do Pronasci instituiu ainda os seguintes projetos:

I) Reservista-Cidadão;

II) Proteção de Jovens em Território Vulnerável (Protejo);

III) Mulheres da Paz; e

IV) Bolsa Formação.

\section{Dimensões da gestão}

A coordenação em vários níveis de governo (interfederativa), entre diferentes órgãos governamentais (intergovernamental) e dentro dos órgãos (intragovernamental) tem sido uma ferramenta fundamental para a implementação de programas que exigem atuação conjunta e complexa de atores variados. Para implatação do programa foi necessário fazer largo uso desse expediente.

\section{Coordenação interfederativa}

Tradicionalmente, o tema de segurança pública no Brasil tem sido de responsabilidade dos estados ${ }^{11}$. Entretanto, devido à complexidade e multidimensionalidade das questões envolvidas, identificou-se a necessidade de nova abordagem que integrasse os esforços dos demais entes federativos. Assim, em 2003 foi celebrado um "Protocolo de Intenções" entre a União, os estados e o Distrito Federal, estabelecendo um sistema de interlocução entre a Senasp, as secretarias de Segurança Pública estaduais e os departamentos de Polícia Federal (DPF) e de Polícia Rodoviária Federal (DPRF), com o objetivo de identificar os principais focos de criminalidade e violência, além de propor soluções conjuntas no âmbito do Sistema Único de 
Segurança Pública. A operacionalização da estratégia se deu pela criação dos Gabinetes de Gestão Integrada Estaduais (GGIE), cuja função é promover a articulação interinstitucional, o planejamento sistêmico e a reforma das polícias, introduzindo mecanismos de gestão com foco na criminalidade segundo os estados e regiões.

Essa nova abordagem também reconhece o papel do município no combate à criminalidade, em especial por meio das Guardas Municipais. No âmbito do Pronasci, e primordialmente nos "Territórios da Paz", instituíram-se os Gabinetes de Gestão Integrada Municipal (GGIM) ${ }^{12}$, que, semelhantes aos GGIE, articulam a atuação das forças de segurança - polícias civil, militar, bombeiro, guarda municipal, secretaria de segurança pública - e representantes da sociedade civil, além de fomentar o debate sobre segurança pública no município e trazer informações sobre os projetos da iniciativa que podem ser implementados no município.

Com base nessa concepção, o Pronasci tem sua formulação centrada na esfera federal e a sua implementação é descentralizada nos estados e municípios, caracterizando um "sistema complexo de incentivos e sanções para a implementação de políticas"13. Apresenta uma estrutura horizontalizada, com ativa participação dos entes subnacionais. Não houve, todavia, um formato único, uma vez que singularidades locais demandam modelo particular de gestão para cada convênio. Tais acordos estabeleciam condicionalidades por parte de estados e municípios, comoa criação de unidades gestoras nos municípios e a garantia de pleno funcionamento dos GGIE e GGIM.

Por intermédio do Pronasci são repassados recursos por meio de convênios para os estados e municípios, que devem guiar sua atuação pelas decisões tomadas nos GGIM e GGIE, promovendo o empoderamento local e atuação equilibrada entre prevenção e repressão. Em outubro de 2010, havia convênios firmados com 25 estados e o Distrito Federal e 174 municípios $^{14}$.

\section{Coordenação intergovernamental}

A articulação com outros órgãos é de grande importância para o Pronasci, já que alguns dos projetos integrantes dos Territórios de $\mathrm{Paz}^{15}$ encontram-se sob a condução de outros ministérios, muito embora nem todas essas ações possuam o mesmo público-alvo. O programa, nesse sentido, também tem por função assegurar que jovens e profissionais de segurança pública tenham acesso aos diversos programas sociais executados pelo estado, buscando um sistema de segurança pública mais efetivo. A ampliação dos recursos orçamentários destinados ao Pronasci possibilitou a expansão dos programas setoriais existentes nos demais ministérios. Pelos termos de cooperação firmados com 14 outros ministérios, o MJ disponibilizou recursos que, por meio de repasses, permitiram a implementação de programas nos 'Territórios de Paz'. Exemplos dessa cooperação são: Pontos de Cultura; Programa de Educação Profissional para Jovens e Adultos (Proeja) e cursos preparatórios para o Exame Nacional do Ensino Médio (Enem), atuação do Programa de Saúde na Família nos territórios; ações de conscientização do consumidor; Plano Nacional de Habitação para profissionais da Segurança Pública; Projeto de Economia Solidária; recuperação de espaços urbanos e áreas degradadas em comunidades carentes ${ }^{16}$.

\section{Coordenação intragovernamental}

O esquema abaixo, extraído da Portaria MJ no 2.736, de 19 de agosto de 2009, que 


\begin{tabular}{|c|c|}
\hline \multicolumn{2}{|c|}{ Gestão do Programa Nacional de Segurança Pública com Cidadania (Pronasci) } \\
\hline $\begin{array}{l}\text { Coordenação Nacional } \\
\text { do Pronasci }\end{array}$ & $\begin{array}{l}\text { Define as diretrizes do programa e elabora a } \\
\text { orientação estratégica }\end{array}$ \\
\hline & $\begin{array}{l}\text { Composição: } \\
\text { Ministro da Justiça - presidente } \\
\text { Secretário executivo do Ministério } \\
\text { Secretário executivo do Pronasci } \\
\text { Secretário Nacional de Segurança Pública }\end{array}$ \\
\hline $\begin{array}{l}\text { Comitê Gestor do } \\
\text { Pronasci }\end{array}$ & Promove a implantação dos projetos \\
\hline $\begin{array}{l}\text { 个 } \\
\text { Relatório quinzenal } \\
\text { sobre a execução dos } \\
\text { convênios, termos de } \\
\text { parceria e execução } \\
\text { direta do programa }\end{array}$ & $\begin{array}{l}\text { Composição: } \\
\text { Secretário executivo do Pronasci - coordenador } \\
\text { Secretário Nacional de Justiça } \\
\text { Secretário de Direito Econômico } \\
\text { Segurança Assuntos Legislativos } \\
\text { Secretário de Reforma do Judiciário } \\
\text { Diretor-geral do Departamento Penitenciário } \\
\text { Nacional; } \\
\text { Diretor-Geral do Departamento de Polícia } \\
\text { Rodoviária Federal; } \\
\text { Assessoria e equipe de apoio do Secretário- } \\
\text { Executivo do Pronasci. }\end{array}$ \\
\hline $\begin{array}{l}\text { Comissão de Acompa- } \\
\text { nhamento da execução } \\
\text { de ações do Pronasci - } \\
\text { CAE }\end{array}$ & $\begin{array}{l}\text { Efetua o companhamento da execução } \\
\text { física, orçamento e financeira dos } \\
\text { convênios e dos termos de parceria } \\
\text { celebrados no âmbito do Programa, bem } \\
\text { como das ações de execução direta. }\end{array}$ \\
\hline $\begin{array}{l}\text { Comitê de Articulação } \\
\text { local }\end{array}$ & $\begin{array}{l}\text { Composição: } \\
\text { Um representante de cada membro do Comitê } \\
\text { Gestor }\end{array}$ \\
\hline \multicolumn{2}{|c|}{$\begin{array}{l}\text { I) promover avaliação, monitoramento e acompanhamento da implementação das ações do } \\
\text { Pronasci, caracterizando-as como vertentes da política de prevenção de segurança pública e } \\
\text { violência; } \\
\text { II) incentivar o caráter federativo do programa e o papel indutor da união na implementação } \\
\text { da política de segurança pública; } \\
\text { III) promover a articulação direta do Pronasci com os Gabinetes de Gestão Integrada } \\
\text { Estaduais e Municipais; } \\
\text { IV) acompanhar a alimentação e utilização do Sistema de Monitoramento e Avaliação do } \\
\text { Programa (Simap); } \\
\text { V) acompanhar a execução dos convênios e termos de parcerias firmados. }\end{array}$} \\
\hline
\end{tabular}

Fonte: elaboração própria, com base no disposto na Portaria MJ nº 2.736, de 19 de agosto de 2009. 
disciplina a gestão do Pronasci, traz um resumo esquemático do fluxograma de gestão do programa dentro do Ministério da Justiça, bem como o papel do órgão na coordenação e acompanhamento dos comitês de articulação locais nos estados.

Um ponto a se destacar na gestão do programa é o constante diálogo entre as secretarias Executiva ede Planejamento, Orçamento e Administração (Spoa). Esta última prepara e envia à Secretaria Executiva relatórios gerenciais regularmente, com as principais informações e desenvolvimentos sobre as ações do Pronasci e os seus planos internos (PI). A disponibilidade das informações possibilita o intercâmbio de recursos entre PI em diferentes estágios de execução e, consequentemente, uma melhor decisão acerca da alocação de recursos para os objetivos desejados.

Isso não deve ser compreendido como garantia de recursos para todas as ações. A distância entre o inicio da elaboração do orçamento e sua execução tem prejudicado o planejamento estratégico ${ }^{17}$ do uso eficiente dos recursos disponíveis.

Cada secretaria do MJ dispõe de um ordenador de despesas responsável pela prestação de contas junto à Spoa. Com base no planejamento de gastos anuais, as secretarias solicitam recursos à Spoa que, por sua vez, encaminha o pedido à Secretaria Executiva com suas recomendações. Ao final do ano, com a liberação de parcela dos recursos contingenciados pela Secretaria de Orçamento Federal, a Spoa passa a dispor de considerável quantidade de recursos a ser rapidamente empenhada.

Nesse difícil contexto de planejamento financeiro, os relatórios mensais encaminhados pela Spoa, nos quais constam os prazos para que as unidades gastem os recursos, sob pena de serem repassados a outras unidades, tornam-se ferramenta indispensável para o planejamento das demais secretarias.

\section{O Projeto Bolsa Formação}

\section{Apresentação do projeto}

O projeto Bolsa Formação foi concebido como uma ação destinada a promover a qualificação e valorização dos profissionais de segurança pública. Em uma

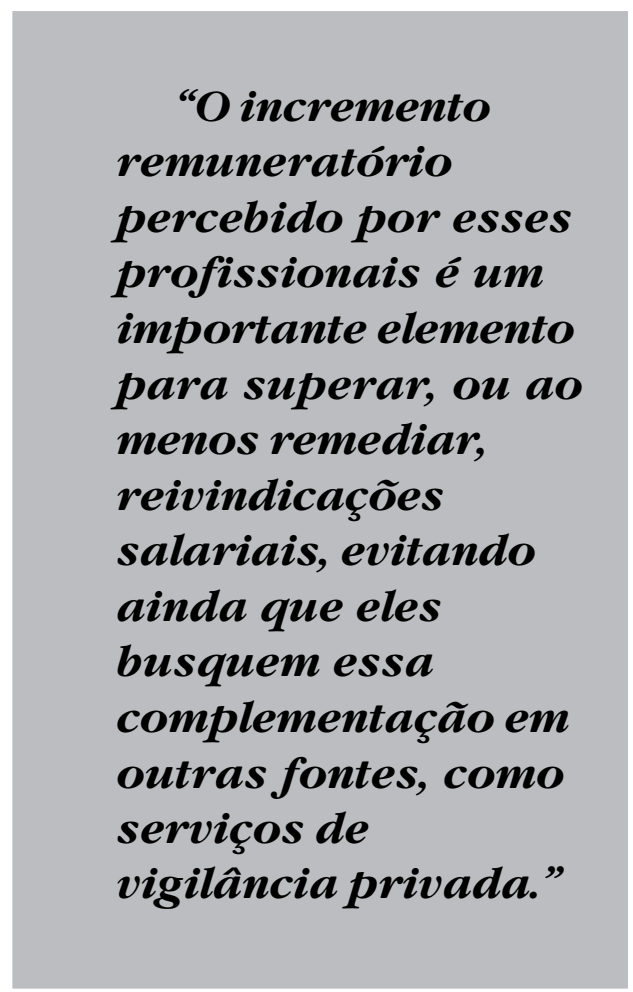

sucinta definição, o Bolsa Formação consiste em uma remuneração adicional, paga aos agentes de segurança pública, tendo como contrapartida a sua participação em cursos de formação ou de educação continuada habilitados pelo Ministério da Justiça.

O valor da bolsa recebida é uniforme para todos os beneficiários - $\mathrm{R} \$ 400$ por 
mês - independentemente da corporação a que pertence o profissional, do seu salário (desde que limitado ao valor estipulado) ou de quaisquer outras variáveis. Podem participar do Bolsa Formação os seguintes profissionais de segurança pública: policiais militares e civis, corpo de bombeiros, peritos, agentes penitenciários e guardas municipais. Para tanto, é necessário que o respectivo estado ou município da federação adira ao Pronasci.

Após o cadastramento e aprovação do benefício, o profissional recebe a bolsa pelo período de 12 meses. Após esse período, não há renovação automática, devendo ocorrer novo credenciamento, quando será analisado o cumprimento das condicionalidades, incluindo a conclusão de um curso habilitado.

A ação tenta resolver, por meio de duas frentes conjuntamente articuladas, o problema da desmotivação, da pouca valorização e da baixa qualificação desses profissionais. $\mathrm{O}$ incremento remuneratório percebido por esses profissionais é um importante elemento para superar, ou ao menos remediar, reivindicações salariais, evitando ainda que eles busquem essa complementação em outras fontes, como serviços de vigilância privada.

A grande inovação do Bolsa Formação é atrelar o benefício pecuniário à qualificação profissional obrigatória. Essa conjugação deve ser compreendida como o cerne indissociável do projeto. Trata-se de uma engenhosa manobra de política pública, que gera grande incentivo aos profissionais, para que eles frequentem os cursos de formação ou de educação continuada, proporcionando melhoria cultural e de qualificação desses trabalhadores.

Um ponto que merece reflexão no projeto é que o valor da bolsa não é proporcional ao número de programas educacionais concluídos pelo profissional. Isso significa que o benefício terá valor fixo independentemente do número de cursos (cumprida a exigência mínima de um a cada 12 meses). Em princípio, podese afirmar que esse aspecto não cumulativo do projeto gera desestímulo à busca por qualificação por parte desses profissionais, e se não seria o caso de instituir um benefício gradual, que cresce juntamente com o número de cursos que o profissional se dispuser a fazer. Essa, todavia, é uma hipótese que merece mais investigação.

O Bolsa Formação pode ser considerado um projeto central e estratégico do Pronasci. Em 2009, do total de recursos cerca de R \$ 1,4 bilhão-inicialmente previstos para o programa, $\mathrm{R} \$ 620$ milhões (44\%) foram destinados ao Bolsa Formação ${ }^{18}$.

Conforme o art. 10 do Decreto 6.490/08, são exigências para participação no Bolsa Formação: 1) receber salário bruto de até $\mathrm{R} \$ 1.700,00 ; 2)$ não ter cometido nem ter sido condenado pela prática de infração administrativa grave ou não possuir condenação penal nos últimos cinco anos; e 3) frequentar, a cada doze meses, ao menos um dos cursos oferecidos pela Secretaria Nacional de Segurança Pública (Senasp) ou pelo Departamento Penitenciário Nacional (Depen) do MJ.

No que tange aos cursos disponíveis aos profissionais, merece destaque o empenho e avanço no sentido de promoção da educação a distância. Trata-se, aliás, de um caso que revela a importância das tecnologias de informação na superação de barreiras para a qualificação profissional. Considerando a abrangência do território nacional e a necessidade de atender à demanda educacional de diversas 
regiões do país, a educação a distância parece se apresentar como uma solução natural.

Para a realização desses cursos, a Senasp fez parceria com a Academia Nacional de Polícia para a criação da Rede Nacional de Educação a Distância. Conforme descrito no sítio do MJ, "com a implementação da Rede, iniciouse novo paradigma, em que a Senasp passou a exercer o papel de efetivo órgão condutor dos processos de educação em segurança pública, promovendo a articulação das academias, escolas e centros de formação e aperfeiçoamento dos operadores de segurança pública, obviamente em um quadro de respeito aos princípios federativos"19. Em conformidade com o MJ, a rede está implantada em todos os estados brasileiros, com mais de duas centenas de telecentros que garantem o acesso dos profissionais aos cursos on-line.

\section{Contexto e decisão de criar a política (entrada na agenda governa- mental)}

A articulação realizada pelo ministro da Justiça foi citada como impulso fundamental para a concretização do Pronasci, além do acúmulo de experiências prévias, que possibilitou avanço no sentido da consolidação de projetos como o Bolsa Formação.

Em 2007, ganhou força a ideia de se estabelecer um piso salarial unificado para as categorias de policiais, bombeiros, peritos e guardas municipais. O MJ dispunha de recursos para realizar tal ideia, mas havia dificuldades financeiras nos níveis estadual e municipal, além da falta de apoio político. Assim, restava ao ministério esboçar, dentro de um período relativamente curto, um projeto que contemplasse o uso desses recursos para o aumento remuneratório proposto.

Inicialmente foi considerado o repasse direto de uma bolsa para os profissionais, sem contrapartidas. Entretanto, diagnósticos feitos pela área de educação da Senasp apontavam para um segundo problema: a ausência de formação adequada dos profissionais de segurança pública. Mais ainda, verificou-se que muitos profissionais que trabalhavam fora das regiões metropolitanas se encontravam à margem dos processos de capacitação e qualificação profissional. Da conjugação das diretrizes do programa (valorização dos profissionais de segurança pública) com esses diagnósticos foi gerado um modelo que incorporaria educação à concessão de bolsas - o Bolsa Formação.

\section{Processo de formulação}

Dentro da própria Senasp havia ideias variadas para a estrutura do projeto. Alguns defendiam escalonamento de benefícios, respeitando a hierarquia das corporações. Embora essa fórmula tenha prevalecido nos primeiros meses de implementação, o baixo número de bolsas efetivamente concedidas (763 em um universo de três mil solicitações) ensejou uma revisão do projeto, que passou a contemplar uma bolsa de valor único para todos os profissionais que percebessem remuneração abaixo de $R \$ 1.400$ (posteriormente esse limite foi aumentado para $\mathrm{R} \$ 1.700)$.

O cálculo da remuneração também foi ponto de discussão na fase de formulação da política. Preferiu-se considerar, para fins do teto da remuneração, somente as gratificações permanentes de acordo com a Lei 8.112/90, não se considerando verbas de caráter indenizatório (auxílio-moradia e vale-transporte). 


\section{Processo de implementação}

O modelo de gestão adotado apresenta estrutura flexível, havendo margem para estados e municípios adaptarem o projeto ao contexto local. Foi construída uma cooperação entre governo federal e os GGIM e os GGIE, sendo os gabinetes responsáveis pela gestão local. Inicialmente, é designado um representante de cada corporação profissional, responsável por conferir se os candidatos cumprem os requisitos para participação no projeto. Em um segundo momento, o gestor estadual consolida e verifica a validade dos dados. O gestor federal, por sua vez, tem o papel de homologar as decisões tomadas, realizando a interface com a Caixa Econômica Federal para o pagamento da bolsa (a "estrutura triangular", ver item 4.5 abaixo).

A área de tecnologia de informação teve papel ativo na implementação do projeto, com o desenvolvimento de sistemas customizados para gestão e monitoramento do Bolsa Formação. A implementação do Simap/Sisfor permitiu o aprimoramento da gestão do projeto.

O Sistema de Monitoramento e Avaliação do Pronasci (Simap) é uma ferramenta pela qual se busca consolidar informações relevantes sobre o programa, facilitando sua gestão e monitoramento. Consoante o relatório de avaliação apresentado pela FGV Projetos (ver item 4.5 abaixo), o sistema representa um choque de inteligência estratégica, sendo uma fundamental ferramenta integradora de dados. No âmbito do Simap, foi criado o Sistema Projeto Bolsa Formação (Sisfor), no qual os profissionais de segurança pública se cadastram e pleiteiam o benefício da bolsa, e os gestores estaduais e federais analisam as informações recebidas.
A implementação do Bolsa Formação em um território pode ser decomposta nas seguintes fases:

- Contratação com governo estadual ou municipal (Termo de Adesão);

- Elaboração de diagnósticos referentes ao número de policiais;

- Assinatura de convênios com as secretarias estaduais de segurança pública; e

- Monitoramento contínuo da participação dos profissionais de segurança pública nos cursos.

Entretanto, nem sempre há coerência entre o planejamento e a disponibilização dos recursos humanos, materiais, financeiros e informacionais. Por exemplo: Apesar da relevância do Bolsa Formação no orçamento do Pronasci, foi constatada a ausência de corpo de servidores efetivos dedicados exclusivamente ao projeto (quase a totalidade de colaboradores eventuais, contratados temporários ou comissionados), o que contribui para a alta rotatividade do quadro de pessoal.

Em março de 2009, o Bolsa Formação beneficiava quase 150 mil profissionais de segurança pública, distribuídos conforme o gráfico 1. Deve-se ressaltar o fato de que cerca de $75 \%$ dos beneficiados são policiais militares.

O Gráfico 2, por sua vez, mostra a distribuição dos beneficiados do Bolsa Formação por unidade da federação no mesmo período. Os estados do Rio de Janeiro e do Rio Grande do Sul apresentam maior índice de beneficiados. Isso se deve ao alto número de policiais recebendo salários abaixo da faixa estabelecida pelo projeto.

A respeito dos desafios e metas futuras, os principais atores entrevistados (em especial da Secretaria Executiva) revelaram uma preocupação com a continuidade do Bolsa Formação após o término do atual 


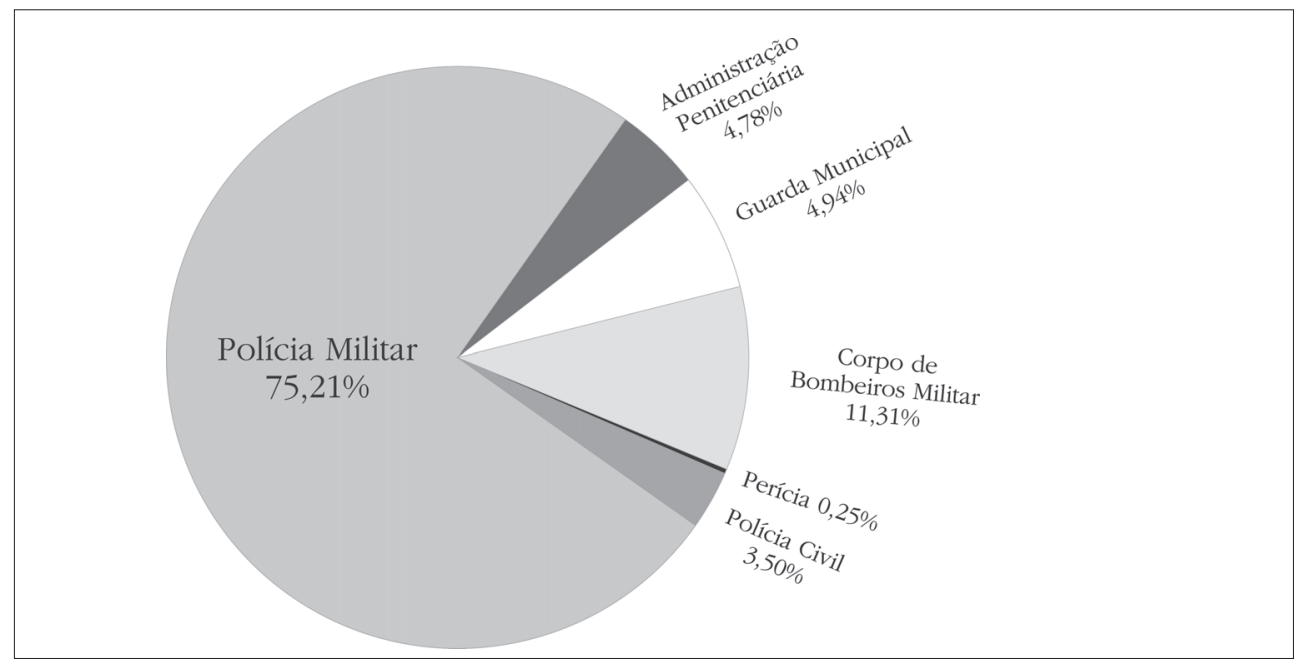

Fonte: Secretaria Nacional de Segurança Pública/Ministério da Justiça - Sistema Nacional do Projeto Bolsa-Formação

Gráfico 1: Distribuição das Bolsas-Formação por corporações de segurança pública - Fev 2009

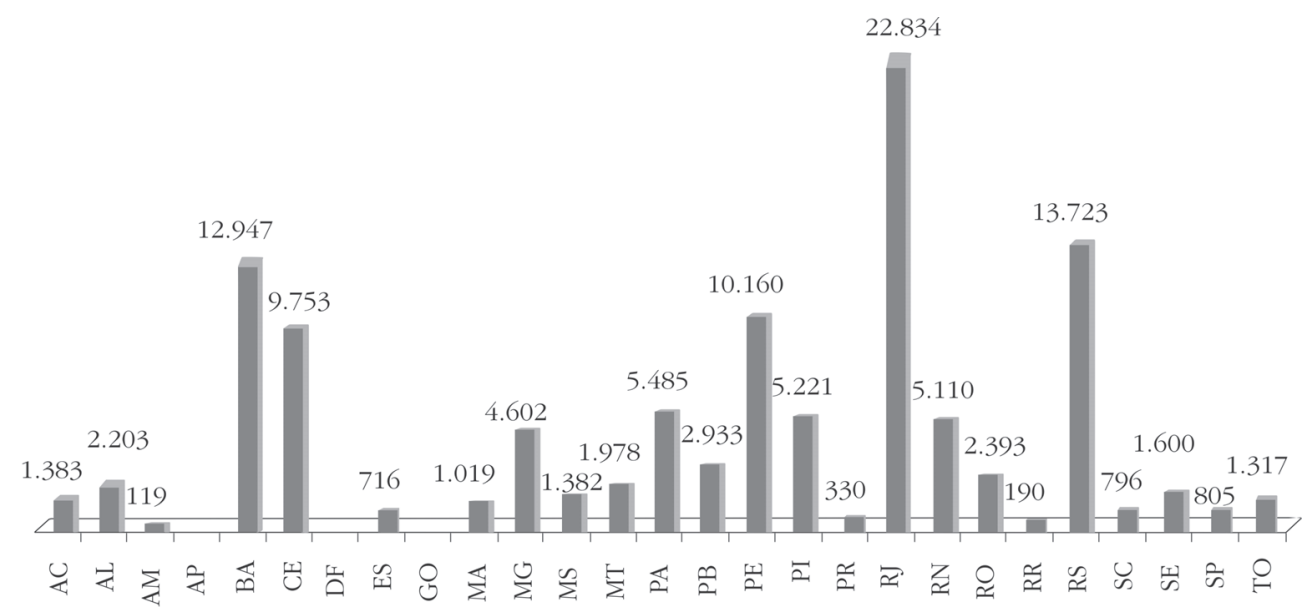

Fonte: Secretaria Nacional de Segurança Pública/Ministério da Justiça

Gráfico 2: Número de beneficiados pelo Projeto Bolsa-Formação por Unidade da Federação - Fev 2009 


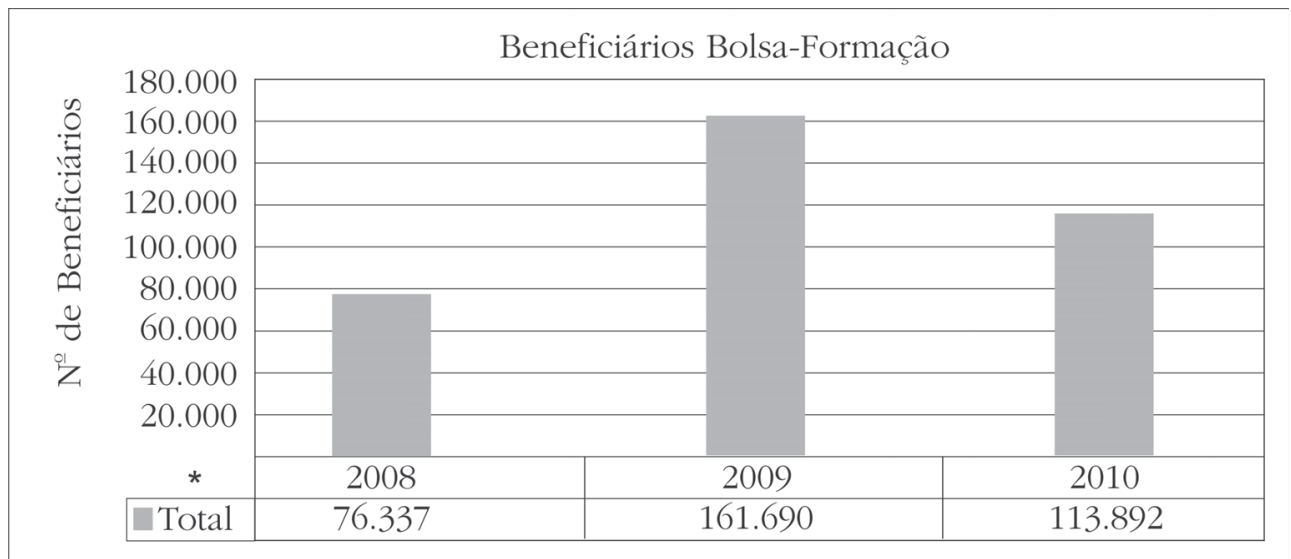

Fonte: Secretaria Executiva do Pronasci - Ministério da Justiça

* Os dados de 2010 contabilizam os beneficiários até 31 de julho.

Gráfico 3: Valorizando do profissional e segurança pública Bolsa-Formação - o governo em contato direto com os policiais

governo. No lado dos profissionais beneficiados, a bolsa parece ter sido incorporada à remuneração fixa, o que torna esses atores um grupo de pressão relevante para manutenção da política.

\section{Controle, monitoramento e avaliação \\ Considerando a relevância do Bolsa} Formação para o Pronasci, os atores envolvidos empenharam-se na construção de um sistema de controle e avaliação. A partir de análise conjunta das informações coletadas, foi possível identificar três esferas ou âmbitos desse sistema que, agindo de maneira interligada, tentam realizar o acompanhamento do projeto.

A primeira etapa do sistema constitui um mecanismo de controle conjugado à implementação do Bolsa Formação. Tratase do procedimento adotado para a aprovação e pagamento das bolsas, envolvendo os atores relevantes de praticamente todos os níveis de governo envolvidos.

O objetivo inicial era de que os dados e informações individuais dos profissionais fossem analisados e monitorados pelos gestores locais e pelos representantes institucionais das corporações, mais próximos dos beneficiados e com mais

\section{Etapas do Controle e Avaliação}

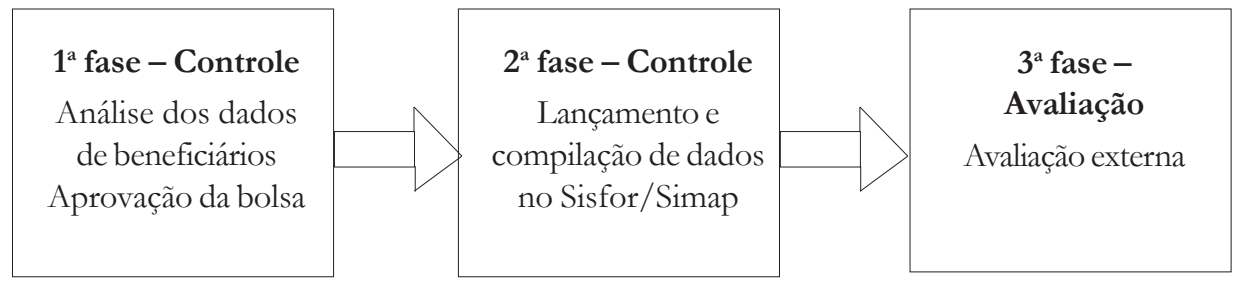


chances de detectar eventuais fraudes. Conforme a descrição constante da página do Bolsa Formação:

"Para gerir o Projeto Bolsa Formação o estado [ou município] nomeará um gestor estadual e cinco representantes de instituições de segurança pública e justiça criminal que farão parte de uma coordenação estadual intersetorial. O grupo que for definido verificará a idoneidade das informações cadastradas e sua homologação, além de promover a articulação com o governo federal" ${ }^{20}$.

Já aos gestores federais caberia a função de compilar as informações de todos os habilitados e verificar eventuais inconsistências, homologando o resultado e determinando o pagamento do benefício pela Caixa Econômica Federal. O esquema abaixo fornece uma descrição visual de tal controle, identificando o papel dos atores no sistema.
A segunda etapa do sistema de controle é o lançamento dos dados e informações no Simap/Sisfor. Esses sistemas foram aprimorados durante o processo de desenvolvimento, o que possibilitou a elaboração de relatórios consolidados e tornando-se importante ferramenta de controle dos gestores.

Por fim, mencionamos a avaliação externa do Bolsa Formação, contratada pelo Ministério da Justiça a uma consultoria externa. $\mathrm{O}$ trabalho de avaliação realizado pode ser dividido em dois blocos. Num primeiro, a consultoria realizou um trabalho de avaliação de todo o Pronasci, incluindo o conjunto completo de suas ações ${ }^{21}$.

Já o segundo trabalho foi uma avaliação qualitativa específica do Bolsa Formação, por questionário enviado por e-mail a todos os profissionais que recebem o benefício. No total, foram obtidas 23.540 respostas, com membros de todas as corporações. Ao final, foi feita avaliação de conteúdo do conjunto de respostas. No geral, as opiniões dos beneficiados sobre o programa são

Sistema de aprovação e controle de bolsas

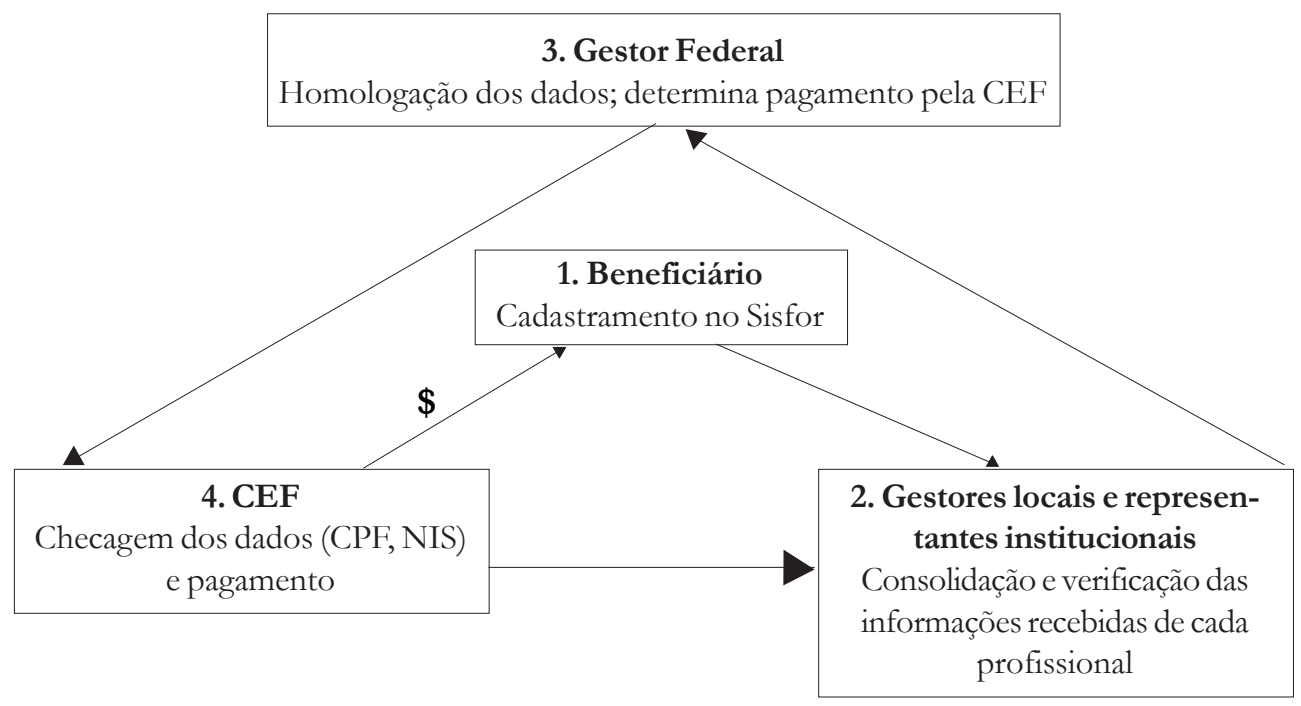


positivas. A principal crítica, contudo, foi referente ao contexto da segurança pública nos estados. No relatório, são inclusas diversas manifestações dos beneficiários com relação ao projeto. Os principais tópicos são a valorização profissional e a melhoria do serviço de segurança pública.

\section{Mulheres da Paz}

\section{Apresentação do projeto}

O projeto 'Mulheres da Paz' tem como objetivo capacitar lideranças femininas que moram em territórios com alto índice de violência e criminalidade, para que elas ajudem jovens em situação de risco e vulnerabilidade social. Tais mulheres são responsáveis, entre outras tarefas, por encaminhar os membros da comunidade aos demais projetos desenvolvidos pelo Pronasci como essa iniciativa e o 'Reservista-cidadão'.

As mulheres da paz são escolhidas por meio de processos seletivos públicos realizados pelos gestores locais (municípios ou estados), com base em critérios definidos como relevantes para o projeto (escolaridade, reconhecimento como liderança comunitária, residência em locais identificados como foco do Pronasci). As mulheres selecionadas passam por treinamento em temas como cidadania, direitos humanos e mediação de conflitos.

O trabalho consiste em visitar as famílias da comunidade para identificar casos de violência, abusos, uso de drogas, evasão escolar, entre outros. Os casos são registrados e encaminhados às equipes multidisciplinares e para os Centros de Referência de Assistência Social (Cras), responsáveis por tentar minorar os problemas e promover a reinserção dos jovens na comunidade por meio de atividades culturais, educativas e de capacitação profissional.

A equipe multidisciplinar e os gestores locais também são responsáveis pelo registro das informações no SIMPaz - sistema desenvolvido pelo MJ para o acompanhamento e controle do projeto -, que permite a coleta dos dados referentes ao cumprimento das tarefas pelas mulheres da paz.

Cada uma das mulheres participantes recebe mensalmente uma bolsa de $\mathrm{R} \$ 190$, desde que cumpra as metas estabelecidas

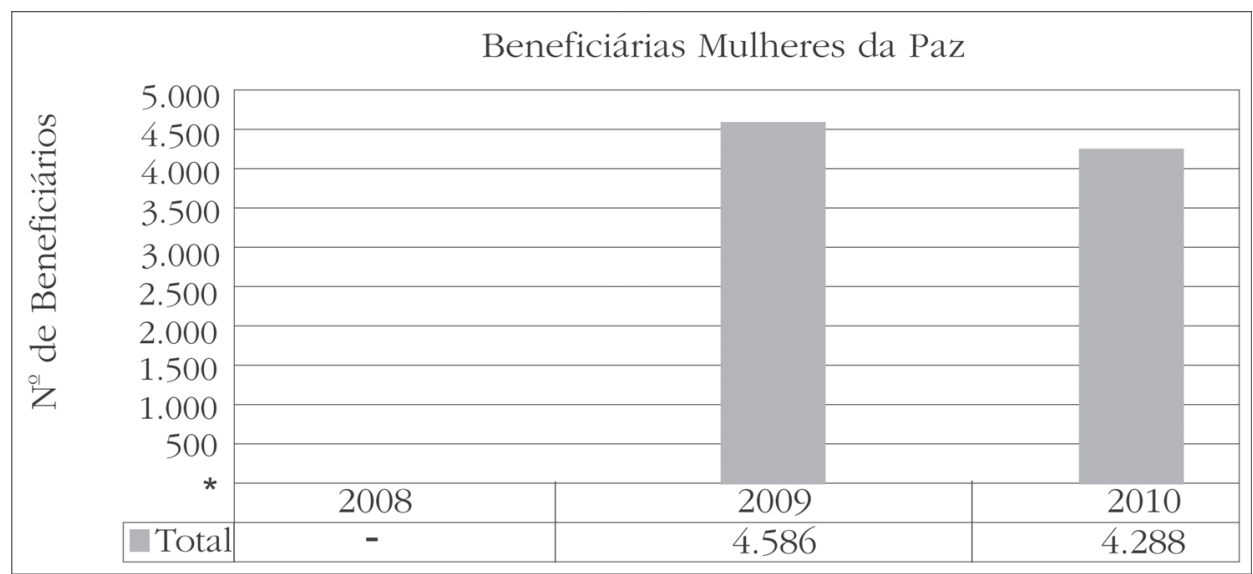

Fonte: Secretaria Executiva do Pronasci - Ministério da Justiça

* Os dados de 2010 contabilizam as beneficiadas até 31 de julho.

Gráfico 4: Mulheres em Ação - Mulheres da Paz 
pelo gestor local. Além da bolsa, as mulheres da paz têm a oportunidade de participar de cursos profissionalizantes que lhes possibilitem realizar uma atividade produtiva sustentável.

\section{Contexto e decisão de criar a política (entrada na agenda governamental)}

Um dos fatores mais relevantes para a entrada do tema na agenda governamental foi a interlocução do MJ com grupos da sociedade civil. No começo de 2007, foram realizados colóquios temáticos, envolvendo governo, academia e sociedade civil, entre os quais mereceu destaque um encontro que tratou especificamente do papel das mulheres nessa nova fase de atuação do poder público no combate à violência. Além disso, na discussão com grupos como as "Mães de Acari" e a Central Única de Favelas (Cufa) foi levantado o conceito de comunidades "maternocentradas", o que significa que a figura das mães carrega grande carga de respeito nas periferias metropolitanas.

Com base nesse conceito, é elaborado um primeiro projeto chamado "Mães Ouvidoras", que posteriormente deu origem ao 'Mulheres da Paz'.

\section{Processo de formulação}

A formulação do projeto ocorreu em diferentes fases. Tendo como base a ideia inicial das 'Mães ouvidoras', o projeto de lei foi encaminhado ao Congresso Nacional contemplando o nome inicial "Mães da Paz", juntamente com a proposta de criação do Pronasci, aprovada pela Lei 11.530/07. Em tal proposta, foi definido o grupo focal da atuação das mulheres envolvidas no programa como "jovens em situação de vulnerabilidade social e em conflito com a Lei”22.
Nesse ponto, o nome 'Mães da Paz' foi colocado em questionamento pela Secretaria Especial de Políticas para as Mulheres (SPM) e por parte da militância de defesa dos direitos das mulheres, sob o argumento de que o termo 'mães' limitava o papel dessas mulheres na sociedade e de que a assistência aos jovens é obrigação do Estado e não de mulheres da sociedade civil. Esse primeiro obstáculo teve como resultado prático a troca do nome para "Mulheres da Paz", pela Medida Provisória, no 416, de 2008.

O passo seguinte foi o lançamento do projeto em Brasília, em dezembro de 2007, com a participação de 200 mulheres originárias de regiões metropolitanas que constituem o foco territorial do Pronasci. No encontro, foi delineado o perfil sociodemográfico das futuras participantes do programa (foco territorial e etário; os critérios de seleção e as contrapartidas esperadas das mulheres que recebem bolsa etc.).

Inicialmente, foi imaginado um modelo de gestão federal para o Mulheres da Paz. Nele, tanto a seleção quanto o acompanhamento das mulheres participantes seria realizado pelo Ministério da Justiça. No entanto, a escassez de recursos humanos e a falta de capilaridade exigiram modelo de gestão a partir de convênios, descentralizando a ação para estados e municípios.

Sobre a divisão territorial, optou-se pela seleção baseada na estrutura demográfica dos diferentes territórios. Na prática esse número tem variado bastante, em função da disponibilidade de recursos e das especificidades locais.

Após definir o modelo de gestão, foi preciso construir um sistema de gerenciamento de informações que possibilitasse o acompanhamento e o controle das ações. No caso do Mulheres da Paz, foi dado 


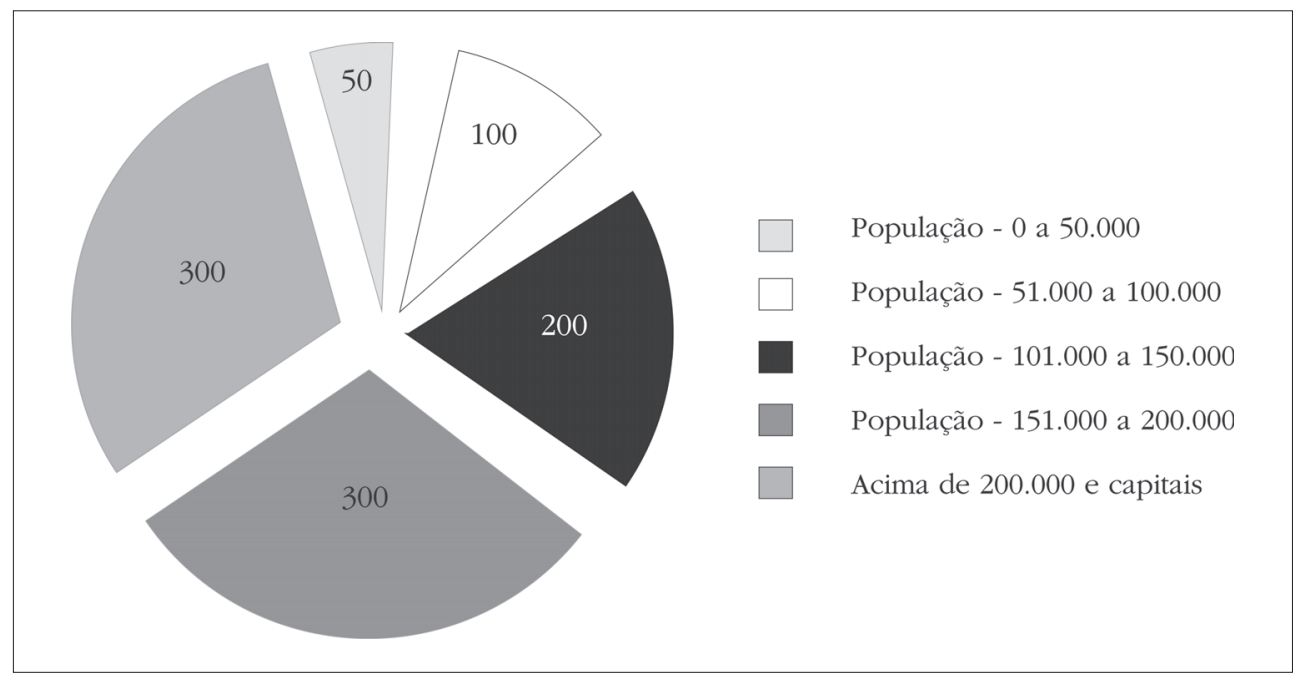

Fonte: Secretaria Nacional de Segurança Pública/Ministério da Justiça

\section{Gráfico 5: Distribuição de Mulheres da Paz por região segundo população}

prazo exíguo para o desenvolvimento de um sistema que permitisse o cadastro das mulheres selecionadas e capacitadas, além do acompanhamento, por parte do gestor federal, do cumprimento das metas estipuladas. Esse sistema foi batizado de SIMPaz.

\section{Processo de implementação}

Após a definição dos focos prioritários para as ações do Pronasci, foram identificados 25 territórios com mais de 50 mil habitantes, sendo iniciadas as negociações com estados e municípios para a celebração dos convênios que definiam a execução do projeto Mulheres da Paz. No momento da negociação do convênio são definidos os territórios para os quais se destinam as ações do projeto.

No primeiro momento do projeto, apenas dois estados (Rio de Janeiro e Acre) conveniaram-se diretamente com o governo federal por meio da Senasp, recebendo recursos, seguidos de Pernambuco.

A execução do projeto ocorre de maneira descentralizada com supervisão da
Senasp pelo SIMPaz. Os convênios firmados entre os entes federados e o MJ estabelecem como responsabilidade dos gestores locais: a) identificação e seleção das mulheres da paz; b) estruturação física e pessoal de equipe multidisciplinar; c) capacitação das mulheres da paz; e d) desenvolvimento das atividades de resgate e reeducação dos jovens em situação de risco social e em conflito com a lei.

Cabe ao MJ o acompanhamento da gestão local dos recursos por meio do SIMPaz, e, após a comprovação do cumprimento das metas negociadas, o repasse das bolsas, operacionalizado pela Caixa Econômica Federal. Tal qual o caso do Bolsa Formação, a comunicação se dá de forma triangular entre os entes federados conveniados, a secretaria e a CEFaixa Econômica Federal (CEF).

A opção de descentralização da gestão do projeto permite a atuação conjunta dos entes federados e o comprometimento de todos para o alcance dos objetivos, além de possibilidade melhor adequação aos 


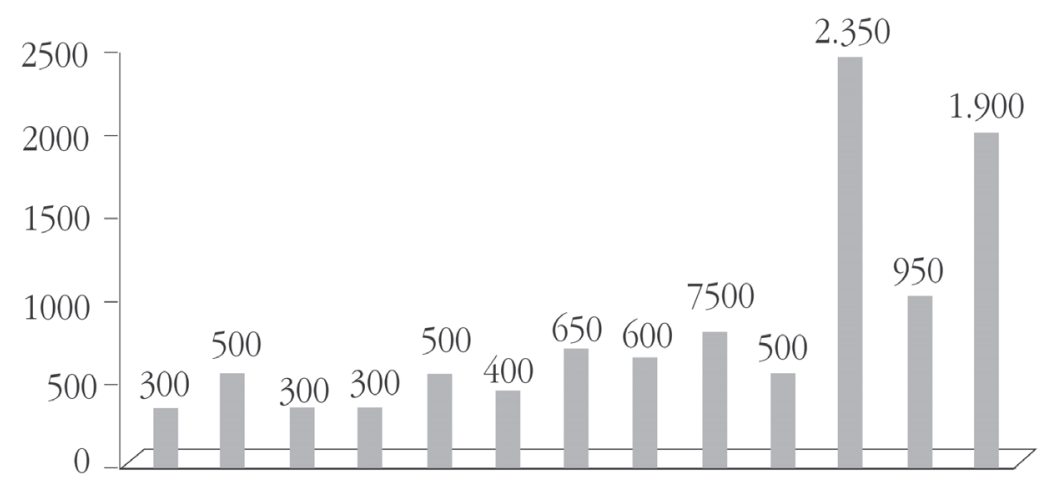

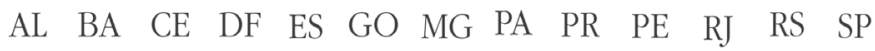

Fonte: Secretaria Nacional de Segurança Pública/Ministério da Justiça

\section{Gráfico 6: Estimativa de distrituição de Mulheres da Paz por região}

casos particulares. Os gestores locais têm contato contínuo com a Senasp e, em alguns casos, recebem capacitação para gerir e administrar o projeto.

Foram identificadas deficiências na relação entre os gestores federais e a Spoa do MJ, evidenciadas pela incerteza quanto aos recursos disponíveis e pela ausência de planejamento de dotações para o projeto. Em março de 2009, não estavam previstas dotações orçamentárias para o projeto no exercício, e havia apenas uma referência ao valor empenhado no ano de 2008 ( $\mathrm{R} \$ 32.065 .643,94)$, quando as ações ainda estavam bastante incipientes. Dessa forma, o orçamento destinado ao Mulheres da Paz parece depender fortemente da articulação da Senasp para obter parcela do orçamento de outras ações do Pronasci.

Controle, monitoramento e avaliação

O gestor local é responsável por grande parte do controle do projeto: contratação da empresa, monitoramento do processo de seleção e capacitação das mulheres; e acompanhamento dos trabalhos e registro das informações no SIMPaz. Uma deficiência a ser apontada é o fato de o gestor federal ter acesso apenas às informações cadastradas pelos gestores locais, sem uma forma de controle efetivo da veracidade e acuidade dos dados.

No início dos trabalhos, as equipes multidisciplinares locais são responsáveis por assessorar as mulheres da paz em seu trabalho com a comunidade e fazer a interlocução com os outros projetos. Posteriormente, tais equipes devem produzir relatórios para o gestor local, responsável pela verificação do cumprimento das metas de contrapartida estabelecidas para cada mulher e pelo registro dos dados no SIMPaz.

Uma vez que o gestor local comprove o cumprimento das metas individuais, devese repassar as informações ao gestor federal (Senasp), responsável pela homologação e emissão da ordem de pagamento para a CEF. 
Com o objetivo de garantir a efetividade e a transparência na implementação do Projeto Mulheres da Paz, o monitoramento e o acompanhamento das ações visa assegurar que o benefício seja repassado às mulheres que atendam às condicionalidades do projeto. Os gestores dos estados e dos municípios fazem o acompanhamento do projeto por meio das seguintes atividades ${ }^{23}$ :

- Reuniões quadrimestrais com os gestores locais do projeto;

- Reuniões com as beneficiárias do projeto;

- Ações in loco e a distância, realizadas pela Secretaria Nacional de Segurança Pública por meio da Comissão Nacional de Acompanhamento e Monitoramento do Projeto conforme critérios e parâmetros estabelecidos;

- Auditorias e ações de fiscalização realizadas pelas instituições de controle interno e externo do poder executivo; e

- Auditorias por meio de análise das bases de dados e sistemas no âmbito estadual, municipal e/ou federal, que permitem identificar duplicidades, divergências de informação de renda, entre outras.

A principal ação de acompanhamento do projeto Mulheres da Paz são reuniões quadrimestrais, reunindo todos os gestores locais, em que são expostas as principais dificuldades, obstáculos e resultados do programa nos estados e municípios. Em 2008, foram realizadas duas reuniões desse tipo, em Brasília, evidenciando que a principal debilidade do projeto, naquele momento, era a falta de capacitação dos gestores locais, o que levou a secretaria a oferecer cursos de capacitação para diversas equipes.

No que se refere à avaliação externa, a principal iniciativa é o contrato com uma consultoria externa para avaliar o Pronasci em seu conjunto. Contudo, até o período mencionado não havia avaliações específicas do Mulheres da Paz (possivelmente devido ao momento ainda inicial das ações do projeto).

\section{Comparação dos projetos e análise de elementos teóricos}

Concluídas as apresentações dos projetos, realizamos nesta parte final uma comparação entre seus principais elementos constitutivos ou características, alinhando-os com alguns conceitos ou abordagens teóricas utilizadas no âmbito da administração e políticas públicas. $\mathrm{O}$ quadro a seguir apresenta um resumo dessa comparação.

Os dois projetos analisados apresentam fortes componentes de coordenação na sua implementação. O Bolsa Formação demandou a constituição de uma vasta rede intergovernamental composta pelos agentes beneficiários, por gestores locais de cada corporação e pelos diversos agentes em nível federal responsáveis pela operacionalização do programa. Para o correto funcionamento, foi necessário estabelecer regras de atuação, distribuir recursos e construir mecanismos coletivos de decisão, controle e retroalimentação.

O Mulheres da Paz, por sua vez, tem como característica, além da coordenação em nível inter e intragovernamental, a participação de atores como organizações não governamentais, movimentos sociais e associações de vítimas da violência. Isso confere um caráter singular ao projeto, pela necessidade de articulação da atuação estatal com outras organizações sobre as quais os gestores não têm governabilidade (embora seja adequado dizer que tais organizações, em geral, possuem objetivos comuns ou convergentes com as metas do projeto). Nesse cenário complexo, o grande 


\begin{tabular}{|c|c|c|}
\hline $\begin{array}{l}\text { Projeto } \\
\text { Caracteristica / fator } \\
\text { analisado }\end{array}$ & Mulheres da Paz & Bolsa-Formação \\
\hline $\begin{array}{l}\text { Dimensões da } \\
\text { coordenação política }\end{array}$ & $\begin{array}{l}\text { Intra, inter e } \\
\text { extragovernamental }\end{array}$ & Intra e intergovernamental \\
\hline $\begin{array}{l}\text { Entrada na agenda } \\
\text { governamental }\end{array}$ & $\begin{array}{l}\text { Inovação; atendimento a } \\
\text { demanda da sociedade civil }\end{array}$ & Janela de oportunidade \\
\hline $\begin{array}{l}\text { Formulação e } \\
\text { implementação }\end{array}$ & Bottom-up; incrementalismo & Top-down; incrementalismo \\
\hline $\begin{array}{l}\text { Controle, avaliação e } \\
\text { monitoramento }\end{array}$ & $\begin{array}{l}\text { Sistema de controle } \\
\text { abrangente (SIMPaz, } \\
\text { relatórios das equipes } \\
\text { multidisciplinares); } \\
\text { monitoramento sistemático } \\
\text { (reuniões quadrimestrais); } \\
\text { avaliação não expressiva }\end{array}$ & $\begin{array}{l}\text { Sistema de controle } \\
\text { abrangente (estrutura } \\
\text { triangular, Sisfor); } \\
\text { monitoramento não expressivo; } \\
\text { avaliação restrita (contratação } \\
\text { externa) }\end{array}$ \\
\hline Continuidade da política & $\begin{array}{l}\text { Desafio da institucionalização; } \\
\text { público-alvo como instrumento } \\
\text { de pressão }\end{array}$ & $\begin{array}{l}\text { Desafio da institucionalização; } \\
\text { público-alvo como instrumento } \\
\text { de pressão }\end{array}$ \\
\hline
\end{tabular}

desafio passa a ser a criação de espaços públicos efetivos de negociação, que garantam a discussão dos problemas por todos os atores envolvidos, em uma tentativa de atuação sinérgica.

No que tange à entrada do problema na agenda governamental, os projetos apresentaram características semelhantes. Todavia, o Bolsa Formação revelou-se mais claramente um exemplo de "janela de oportunidade". Conforme o modelo de fluxos múltiplos ou "multiple streams framework", uma janela de oportunidade é aberta quando os fluxos de problemas ("problem stream”), de políticas públicas ou soluções ("policy stream") e de política ("political stream") se encontram ${ }^{24}$. No caso do Bolsa Formação, foi possível identificar esses três componentes: o problema da segurança pública, baixos salários e desmotivação dos profissionais; os modelos alternativos de segurança preconizados para a $15^{\text {a }}$ edição dos Jogos Pan-americanos (policies); e a conjuntura política favorável (politics). A conjugação desses fatores abriu uma janela de oportunidade que possibilitou a adoção de alternativas ao modelo de segurança pública praticado até então.

A entrada na agenda do programa Mulheres da Paz se deu não só para atender às demandas de grupos sociais, mas também como uma inovação que buscou aliar o papel de líderes comunitárias das mulheres à política de prevenção e mitigação da violência.

A formulação e implementação do Bolsa Formação aproximaram-se de um modelo top-down, no qual há clara separação entre esses dois momentos (Sabatier, 1986), notadamente pela incapacidade participativa dos estados federados à época da tentativa de estabelecimento de um piso salarial unificado. O Mulheres da Paz, por sua vez, nasce de amplo diálogo com atores envolvidos, contribuindo assim para o avanço do pacto federativo, aproximandose mais de uma abordagem bottom-up.

O Bolsa Formação, por limitação ou rejeição dos estados federados à época de sua concepção - financeira e/ou política - reforçou o papel do governo federal na fase de formulação desse projeto - fato propulsor da prevalência da abordagem 
top-down. Em contrapartida, a limitação do governo federal quanto à capilaridade e à disponibilidade de recursos específicos para o Mulheres da Paz em sua criação, além do maior processo participativo, explica a característica marcadamente bottom-up na implementação deste, resultando na descentralização para estados e municípios.

Ademais, nos dois casos puderam ser identificados elementos de incrementalismo ou comparações limitadas sucessivas ${ }^{25}$. No Bolsa Formação, isso é evidenciado pela inviabilidade do projeto inicial, o que levou à necessidade de sua revisão. Já no Mulheres da Paz, as diferentes fases de desenvolvimento do projeto resultaram em um surgimento mais lento e cadenciado.

Quanto aos sistemas de controle, monitoramento e avaliação, os projetos apresentam uma característica muito semelhante. Pode-se afirmar que o controle é o ponto forte nos dois casos, com sistema integrado de intercâmbio de informações, o que é especialmente relevante, tratandose de políticas que demandam descentralização de recursos e atuação interfederativa. No caso do Bolsa Formação, percebe-se que o controle tem como principal objetivo certificar que os recursos serão de fato ofertados para o seu público-alvo profissionais que cumprem os requisitos para recebimento das bolsas. No Mulheres da Paz, além disso, há a verificação das metas de trabalho pelos grupos interdisciplinares.

O monitoramento ${ }^{26}$, por sua vez, é um elemento que se mostrou mais presente no caso do Mulheres da Paz, especialmente se considerar as reuniões quadrimestrais feitas pelo órgão central com os gestores locais, nas quais são relatados acontecimentos relevantes e planejados os próximos $\operatorname{passos}^{27}$. No Bolsa Formação, os relatos coletados e as pesquisas não indicaram ações relevantes no sentido de monitoramento do programa, embora, considerando os seus objetivos (motivação e aumento da remuneração dos profissionais), pode-se argumentar que o sistema de controle já realize parcela da tarefa de monitoramento (ao controlar, por exemplo, o número de profissionais que realizam os cursos e que recebem as bolsas).

$\mathrm{O}$ sistema de avaliação ${ }^{28}$ encontravase em estágio mais avançado no caso do Bolsa Formação. É importante destacar, porém, que o projeto precisa avançar na construção de indicadores que permitam aferir com maior precisão o seu impacto. Conforme relatado, os principais indicadores utilizados para avaliação são o número de profissionais beneficiados e o grau de satisfação, analisado pelo trabalho da FGV Projetos. São obviamente dados relevantes, mas seria importante ampliar essa base avaliativa, a fim de tentar indagar, por exemplo, quais os impactos dos cursos na atuação profissional desses trabalhadores e quais os impactos do benefício pecuniário na gestão de recursos humanos das corporações (rotatividade de profissionais, número de profissionais que trabalham em um segundo emprego, como vigilância privada).

No Mulheres da Paz, até mesmo pelo momento incipiente pelo qual passava o programa à época da pesquisa, não estava explicitamente delineado como seria feita a avaliação da política. Nos dois casos, entretanto, pode-se dizer que a avaliação do projeto não foi pensada desde o início no momento da formulação, o que confirma a prática brasileira nesse sentido. Aqui também, a construção de indicadores de avaliação será um desafio para os gestores do projeto. Considerando que o principal papel das mulheres da paz é atuar como lideranças 
comunitárias e encaminhar jovens e outros para serviços e programas sociais do Estado, é uma tarefa complexa tentar responder qual o efetivo impacto dos trabalhos dessas mulheres em suas comunidades.

Por fim, nos dois casos, a continuidade do programa passa atualmente pelo desafio de sua institucionalização. Existe uma visão partilhada por muitos gestores de que tal prática, por sua vez, depende da existência de mecanismos de avaliação legítimos que comprovem a efetividade do programa, a exemplo do que ocorreu com o Programa Bolsa-Família do governo federal. Outro fator relevante para a continuidade do programa, na visão desses atores, seria a aprovação e adesão do público-alvo, que constituiria o principal grupo de pressão e defesa do programa em governos futuros.

A partir da análise realizada, pode-se afirmar que os dois projetos evidenciam e confirmam a principal inovação do Pronasci, que é aliar à repressão os elementos de prevenção e proteção social. Trata-se de propostas que trazem consigo uma promessa de abordar o tema da segurança pública de forma diferenciada, valorizando os profissionais responsáveis e obtendo o apoio e colaboração da sociedade. Embora seja cedo para contabilizar a totalidade de seus resultados, o apoio e a defesa dos agentes e beneficiários entrevistados revelam que as ideias podem ser consideradas, no mínimo, parcialmente acertadas. Em contrapartida, o estudo dos projetos também revela a presença de algumas fragilidades características da forma de gestão de políticas públicas usualmente realizadas no país.

(Artigo recebido em fevereiro de 2010. Versão final em dezembro de 2011).

\section{Notas}

* Os autores são Especialistas em Políticas Públicas e Gestão Governamental do Ministério do Planejamento, Orçamento e Gestão, lotados em diferentes órgãos da Administração Pública Federal.

${ }^{1}$ O modelo utilizado foi proposto por Ripley (1995), que divide o ciclo de políticas públicas em agenda setting, formulation and legitimation of goals and programs, implemmentation, evaluation e decisions about the future.

${ }^{2} \mathrm{Na}$ abordagem top-down, a decisão de formulação e implementação de determinada política pública se dá nos níveis hierárquicos superiores da burocracia, cabendo aos implementadores diretos da política pública uma participação mais tímida, quando existente, no planejamento das decisões (Oliveira, 2006).

${ }^{3}$ No sentido proposto por Guy Peters (PeTERs, 2004).

${ }^{4}$ Ministério da Justiça, s.d.

${ }^{5}$ Disponível em: [http://portal.mj.gov.br/senasp/data/Pages/MJ3F6F0588ITEMID5786673 656AF443A90A3845457D8243APTBRIE.htm]. Acesso em: 20.11.2010.

${ }^{6}$ Ministério da Justiça, 2009.

${ }^{7}$ IPEA, 2003.

${ }^{8}$ Ministério da Justiça, 2009. 
${ }^{9}$ Disponível em: [http://portal.mj.gov.br/data/Pages/MJ3F6F0588ITEMID431E6CD55 A794327BCAA9EECF55F2604PTBRIE.htm]. Acesso em 20.11.2010.

${ }^{10}$ Sítio do Ministério da Justiça, disponível em: [http:/ / portal.mj.gov.br/senasp/data/Pages/ MJ3F6F0588ITEMIDF0B0F86950A04E478D6229323 A4336F9PTBRIE. htm]. Acesso em: 20.11.2010.

${ }^{11}$ A Constituição Federal de 1988 manteve a competência estadual no art. 144, \ $6^{\circ}$.

${ }^{12}$ Gabinete de Gestão Integrada Municipal é o principal instrumento de articulação entre a polícia e a sociedade. Grupo composto por membros das secretarias municipais envolvidas no Pronasci, que tem por objetivo realizar ações integradas de combate à violência com o apoio de equipes multidisciplinares compostas de assistentes sociais, psicólogos, educadores e pedagogos. Os GGIM constituem um espaço de articulação entre as diferentes forças de segurança - polícias civis, militares, bombeiros, guardas municipais, secretarias de segurança pública - e a sociedade.

${ }^{13}$ SOUZA, 2009.

${ }^{14}$ Disponível em: http://portal.mj.gov.br/data/Pages/MJA4C659C5ITEMID 7015C02E10 C24058877BEB931D5D3594PTBRIE.htm. Acesso em: 22/11/2010.

${ }_{15}$ Acerca do Programa Territórios de Paz ver [http://www.mj.gov.br/data/Pages/ MJ3FD1029CITEMID3442470E4A084A0CB5BC9153D9585A0CPTBRIE.htm]. Acesso em: 12.01.2010.

${ }^{16}$ Disponível em: [http://portal.mj.gov.br/data/Pages/MJ3FD1029CITEMIDFA34A8 C4A1F14C2BBECEDF60C7C0A2ACPTBRIE.htm]. Acesso em: 22/11/2010.

${ }^{17}$ Esses valores não consideram os cortes posteriores feitos na Lei de Orçamento Anual e no Decreto de Contingenciamento.

${ }^{18}$ Disponível em: http://portal.mj.gov.br/data/Pages/MJE9CFF814ITEMIDD9B26EB2E3 CD4 9B79C0F613598BB5209PTBRIE.htm. Acesso em: 14.11.2010.

${ }^{19}$ Disponível em: [http://www.mj.gov.br/data/Pages/MJ6D5A37BFITEMIDE6550B91F78 E48FF815C5DA77D82471DPTBRIE.htm]. Acesso em: 12.01.2010.

${ }^{20}$ Tivemos acesso a dois documentos dentro desse escopo, um datado de dezembro de $2008 \mathrm{e}$ que inclui uma revisão de todo o programa até essa data, além de uma atualização desse relatório realizada em janeiro de 2009.

${ }^{21}$ Projeto Executivo do Programa Mães da Paz, 2008.

${ }^{22}$ Disponível em: [http://portal.mj.gov.br/data/Pages/MJ34F31E13ITEMID9162F3 CADA134E198087CF10E878C8ACPTBRIE.htm]. Acesso em: 22/11/2010.

${ }^{23}$ Kingdon, 1995.

${ }^{24}$ Conforme a concepção do incrementalismo, o número de opções disponíveis ao policy maker vai se reduzindo gradualmente, com o desenvolvimento e as mudanças na política pública. Já na abordagem de "comparações limitadas sucessivas", a escolha das políticas públicas dentre as disponíveis revela as preferências dos atores, reduzindo o número de alternativas disponíveis (LindBLOM, 1959).

${ }^{25}$ Neste texto entendemos monitoramento como um acompanhamento rotineiro de indicadores relevantes e de ações da política, a fim de fornecer um cenário de ação e mapear as alternativas ao gestor. Nesse sentido Vaitsman, Rodrigues e Paes-Souza: "monitoring consists of continuous, routine supervision by managers of the development of programs and policies in relation to their goals and targets" (2006, p.21).

${ }^{26}$ Os pesquisadores acompanharam uma dessas reuniões, realizada no Rio de Janeiro em março de 2009. 
${ }^{27}$ Acerca do conceito de avaliação: "generally speaking, evaluations are carried out by outside institutions through research studies which seek to answer specific questions, propose corrective measures and guide decision makers, managers and other participants in the processes of formulation and implementation. The objective of an evaluation may be to improve the quality of implementation processes or to reap results." (VAitsman, Rodrigues e PAES-SouZA, 2006, p. 23).

\section{Referências bibliográficas}

FLeURY, Sonia. El desafio de la gestión de las redes de políticas. Revista Instituciones y Desarrollo no 12-13, 2002. Institut Internacional de Governabilitat de Catalunya, España.

Kingdon, John W. Agendas, Alternatives, and Public Policies. New York: HarperCollins, 1995. 2nd ed.

Instituto Cidadania. Projeto Segurança Pública para o Brasil. s.d. Disponível em: http:/ / portal.mj.gov.br/data/Pages/MJ3F6F0588ITEMID9BAA91074F7F4 DD3A2B63F 1BF33F6B61PTBRIE.htm. Acesso em: 25.11.2010.

Instituto de Pesquisa Econômica Aplicada - IPEA. Políticas Sociais - Acompanhamento e Análise n 7.2003.

LindBlom, Charles E. The science of mudling through. Public Administration Review, v. 19, p. 79-88, 1959.

Ministério DA JustiçA. s.d. Disponível em: [http://www.mj.gov.br/data/Pages/ MJE24D0EE7ITEMIDAF1131EAD238415B96108A0B8A0E7398PTBRIE.htm]. Acesso em: 22.12.2009.

MinistÉRIO DA JustiçA. Orientações para apresentação de projetos relativos a prevenção da violência e criminalidade no fundo nacional de segurança pública. 2009. Disponível em: [http:/ / portal.mj.gov.br/ services / D ocumentManagement/FileDownload.EZTSvc.asp? DocumentID =\%7B3B4B011C-215E-4C5C-BE42-C417B905A763\%7D\& ServiceInst $\mathrm{UID}=\% 7 B B 78 E A 6 C B-3 F B 8-4814-A E F 6-31787003 C 745 \% 7 D]$. Acesso em: 20.11.2010.

Ministério DA JustiçA. Termo de Referência: Gabinete de Gestão Integrada. s.d. Disponível em: http://portal.mj.gov.br/data/Pages/ MJ3F6F0588ITEMID9BAA 91074F7F4DD3A2B63F1BF33F6B61PTBRIE.htm. Acesso em: 25.11.2010.

Oliveira, Jose Antonio Puppim de. Desafios do planejamento em políticas públicas: diferentes visões e práticas. RAP, Rio de Janeiro 40(1):273-88, Mar./Abr. 2006.

Peters, B. G. Governance and Public Bureaucracy: New Forms of Democracy or New Forms of Control. Asia Pacific Journal of Public Administration 26, 3-16, 2004.

Projeto Executivo do Programa Mães da Paz, 2008.

RIPLEY, Randall. Stages of the policy process. In: Daniel C. McCool. Public policy theories, models, and concepts: an anthology. New Jersey: Prentice Hall, 1995.

SABATIER, Paul. Top down and bottom up approaches to implementation research. Journal of Public Policy, n. 6, 1986. 
Silva, Pedro L.B. e Melo, Marcus A. O processo de implementação de políticas públicas no Brasil: características e determinantes da avaliação de programas e projetos. Cadernos NEPP, $\mathrm{n}^{\circ}$ 48. Campinas: Unicamp, 2000.

SouzA, Celina. Federalismo no Brasil. Palestra na ENAP para o Curso de Formação Inicial para a Carreira de Especialista em Políticas Públicas e Gestão Governamental. Brasília, 2009.

Vaitsman, Jeni; Rodrigues, Roberto W. S.; Paes-Souza, Rômulo. The system for evaluating and monitoring social development programs and policies: the case of the Ministry of Social Development and the Fight against hunger in Brazil. Brasília: UNESCO, 2006. 


\section{Resumo-Resumen-Abstract}

As novas propostas para a segurança pública no Brasil: uma análise comparativa dos projetos Bolsa Formação e Mulheres da Paz

Verônica Sánchez da Cruz Rios; Marcos Cerqueira; Pedro Assumpção Alves e Daniel Gama e Colombo

A partir do exame qualitativo de dados e informações coletadas, lastreado nas teorias do ciclo de políticas públicas, esse texto analisa duas recentes iniciativas do governo federal brasileiro na área de segurança pública - os projetos 'Bolsa Formação’ e 'Mulheres da Paz', ambos do Programa Nacional de Segurança Pública com Cidadania (Pronasci). A partir da descrição e reconstrução histórica desses projetos, tentamos realizar uma comparação entre alguns de seus principais elementos ou características, concatenando-os com conceitos e abordagens teóricas, a fim de trazer conclusões úteis à análise e formulação de políticas públicas.

Palavras-chave: Políticas públicas, segurança pública, Mulheres da Paz, Bolsa Formação.

Las nuevas propuestas para la seguridad pública en Brasil: un análisis comparativo de los proyectos Bolsa Formación y Mujeres de la Paz

Verônica Sánchez da Cruz Rios; Marcos Cerqueira; Pedro Assumpsão Alves e Daniel Gama e Colombo

A partir de un examen cualitativo de datos e informaciones colectados y fundados en las teorías del ciclo de políticas públicas, este texto analiza dos recientes iniciativas del gobierno federal brasileño en el área de la seguridad pública, los proyectos "Bolsa Formação" y "Mulheres da Paz", ambos integrantes del Programa Nacional de Seguridad Pública con Ciudadanía (Pronasci). A través de la descripción y reconstrucción histórica de estos proyectos, tratamos de realizar una comparación entre algunos de sus principales elementos o características, concatenándolos con conceptos y abordajes teóricos, a fin de traer conclusiones útiles al análisis y formulación de políticas públicas.

Palabras clave: Políticas Públicas, Seguridad Pública, Mulheres da Paz, Bolsa Formação.

The new proposals for public security in Brazil: a comparative analysis of projects Training Scholarship and Woman of the Peace

Verônica Sánchez da Cruz Rios; Marcos Cerqueira; Pedro Assumpção Alves e Daniel Gama e Colombo

Based on a qualitative analysis of the data and information gathered and using a public policy cycle approach, this paper aims to examine two recent initiatives of the Brazilian federal government to improve public security, the 'Bolsa Formação' and 'Mulheres da Paz' projects, both part of the National Program of Public Security with Citizenship (Pronasci). By describing and making an historical analysis of these projects, we try to compare some of its main features and characteristics, aligning them with theoretical concepts and frameworks, in order to come up with useful conclusions to the analysis and formulation of public policies.

Keywords: Public policy, public security, Mulheres da Paz, Bolsa Formação. 
Verônica Sánchez da Cruz Rios

Graduada em Relações Internacionais pela Universidade de Brasília (UnB). Especialista em Políticas Públicas e Gestão Governamental (EPPGG), trabalha com o Programa de Aceleração do Crescimento. Contato: verosanchezdcr@yahoo.com.br

Marcos Cerqueira

Graduado em Economia pela Universidade Estadual de Santa Cruz (UESC) e mestre em Administração Pública pela Universidade de Victoria, Canadá. EPPGG, atualmente é responsável pela avaliação de programas na Secretaria Nacional de Esporte Educacional do Ministério do Esporte. Contato: mrncmarcos@gmail.com

Pedro Assumpção Alves

Graduado em Economia pela Universidade Federal de Santa Catarina (UFSC) e mestre em Demografia pela Universidade Estadual de Campinas (Unicamp). EPPGG, atua no Ministério do Desenvolvimento Agrário (MDA), onde exerce a função de coordenar o monitoramento ambiental do Programa de Regularização Fundiária. Contato: pedroassumpa@yahoo.com.br

Daniel Gama e Colombo

Graduado em Direito e mestre em Direito Econômico, ambos pela Universidade de São Paulo (USP). EPPGG, atualmente é Coordenador-geral de Especialização da Escola Nacional de Administração Pública (ENAP). Contato: dgcol@hotmail.com 